\title{
Misconceptions and Inappropriate Solid Waste Management in Small Towns of Ethiopia: Bule Hora Town, Oromia Region, Ethiopia Adane Sirage Ali*
}

Kotebe Metropolitan University, Addis Ababa, Ethiopia

\begin{abstract}
Solid waste challenge in developing countries, like Ethiopia, is aggravated by the malfunctioning of traditional waste management systems due to rapid development and the alarmingly increasing human population. Bule Hora Town, in Ethiopia, is among the most environmentally degraded environment due to the inappropriate traditional solid waste management system. Therefore, this study was intended to investigate the public awareness and concern to the ever worsening environmental pollution and why the traditional waste disposal systems can stay dominant in the town. Data were collected using door-to-door close-ended questionnaire by a simple random sampling technique.

The findings showed that plastics and festal; fruits, chat leaves and vegetables; and metals and cans respectively made $48(+5) \%, 18(+2) \%$ and $11(+3) \%$ of the solid waste pool. Variations in the awareness and concern to various environmental degradation among different age groups was clearly seen where people under the age of forty showed better understanding. Response findings showed that the dominant solid waste disposal system is open air burning (42\%) followed by open field dumping (36\%) showing that the current solid waste management systems is traditional and inappropriate. Moreover, $50 \%$ of the respondent above age 40 and $30 \%$ of the respondents below age 40 believe that open solid waste burning is a good and long stayed tradition; and it is also undeniable that $35 \%$ of the older people related burning of solid waste, particularly during the month of December, has a religion background, which actually is not.
\end{abstract}

Keywords: Bule hora; Solid waste management; Environment; Waste disposal; Waste burning

\section{Introduction}

Waste problems are said to be the mirror of a society [1]. The state of a society is closely related to its economic, historical, cultural, environmental and other aspects. Solid waste problem in developing countries, like Ethiopia, is aggravated by the malfunctioning of traditional waste management systems due to rapid development and the alarmingly increasing human population. Understanding the state of a society therefore, provides a direction to an understanding of the waste problems in that particular society [1]. Conversely, it is possible to understand the state of a society by looking at its waste problems.

In many towns of Ethiopia, urbanization is increasing at a faster rate ever in the history of the country, which puts an immense pressure on municipal services [2]. The rapid urbanization and an increasing consumerism behavior with traditional way of waste disposal resulted in serious challenges. This waste is not being adequately managed because of lack of concern, financial constraint and less priority; as a consequence it has created a serious negative externalities on human and environmental health.

Waste disposal in Bule Hora Town seems up to the individual households and usually people burn plastics, tires, old clothes and others in the street, around their house, and in any open spaces. The smoke from such burning activity is extremely offensive and probably is causing serious human health problems. Plastics and pieces of materials scattered everywhere on the surface or partly buried in the dust together with dusty nature of the area apparently caused complete loss of aesthetics. The population is growing rapidly and it is clear that the amount of waste precipitate is also rapidly growing, which implies that the challenge would be worsened sooner than later. However, the awareness and concern to the environmental degradation due to inappropriate solid waste management could not demand the growing solid waste generation. The present solid waste management, in the eye of the society, seems to be right and appropriate. This study is, therefore, intended to investigate the status of the public concern and awareness to their current solid waste management practices.

\section{Materials and Methods}

\section{Description of study area}

The study would be conducted in Bule Hora Town, the administration center of Bule Hora District. It is located $467 \mathrm{~km}$ south of Addis Ababa, and lies between $5^{\circ} 35^{\prime}$ and $5^{\circ} 63^{\prime} \mathrm{N}$ latitude and $38^{\circ} 15^{\prime}$ and $38^{\circ} 25^{\prime}$ longitude and on altitude of 1893 m.a.s.l. it is paved Addis Ababa Moyale highway, in the Borena Zone of Oromia Region. The town is among the most important smugglers transition zone where contraband items transfer from Kenya to Ethiopia.

The population in the town is alarmingly increasing. The population was $12,718,22784$ and 35,256 respectively. It is the most populated 907 people per $\mathrm{km}^{2}$, compared to 21.1 people per $\mathrm{km}^{2}$ of the overall Borena Zone.

\section{Sampling design}

Data sources and the required data type: All required data were collected both from primary and secondary sources. The primary

*Corresponding author: Adane Sirage Ali, Kotebe Metropolitan University, Sub City Wo. 11, Addis Ababa, Ethiopia, Tel: +251-911149050; Fax: +251-911149050; E-mail: adnansirage@gmail.com

Received January 12, 2018; Accepted January 27, 2018; Published February 03, 2018

Citation: Ali AS (2018) Misconceptions and Inappropriate Solid Waste Management in Small Towns of Ethiopia: Bule Hora Town, Oromia Region, Ethiopia. Int J Waste Resour 8: 324. doi: 10.4172/2252-5211.1000324

Copyright: (c) 2018 Ali AS. This is an open-access article distributed under the terms of the Creative Commons Attribution License, which permits unrestricted use, distribution, and reproduction in any medium, provided the original author and source are credited. 
data were collected from sampled households, commercial houses, restaurants and hotels. Whilst secondary data were collected through thorough review of all available published and unpublished documents from relevant organizations.

In the town, there is no defined land use system, instead all are found mixed together in one basket: hotels, chat selling shops, shopping centers, restaurants and small markets are scattered everywhere mixed together with the residential houses. The sampling frame was determined in such a way that different land uses in the two were incorporated.

Sampling techniques and data collection: The sampling units were divided into non-overlapping groups resulting in representative samples. Sampling points were selected using simple random sampling technique. After selecting the sampling points/sites, the data were collected door to door and directly from the damping sites.

The data collection was done using checklists which were pre-tested prior to the actual field work. The data on solid waste composition and quantity were collected by direction site solid waste analysis method and close-ended questionnaire survey from the open dumping site and garden collection sites. The structured questionnaire was used for the selected households to generate information about their pollution awareness, housing conditions, solid waste handling, solid waste disposal practices and their perception about the common solid waste burning practices.

The onsite determination of the solid waste composition and quantification included sorting, identification and weighing of the sorted solid wastes. The weight of the solid waste generated was measured at source by using portable scales. For statistical accuracy large and frequent samples were taken from randomly selected sampling points in the sampling frame.

Sample size determination: The heterogeneous sampling sites in the sampling frame consisted of a total of 1000 housing units. Sample size (n) of households that participate was determined by using a sample technique [3] formula, given by:

$$
n=\frac{N Z^{2} P Q}{d^{2}(N-1)+Z^{2} P Q}
$$

Where: $\mathrm{N}=$ total number of housing unit

$\mathrm{Z}=$ standardized normal variable and value that corresponding to

$95 \% . \mathrm{CI}=1.96$

$\mathrm{P}=$ housing unit interval (\% of residential houses out of $\mathrm{N}$ )

$\mathrm{Q}=1-\mathrm{P}$ (nonresidential houses, which is $(1-\mathrm{p}) \% \mathrm{~N}$ )

$\mathrm{d}^{2}=$ allowable error $(0.05)$

Therefore, the result, $\mathrm{n}=304$ was the minimum reliable sample size of housing units while six housing units were added to extend the confidence. After this, simple random sampling was used.

\section{Data Analysis}

Both qualitative and quantitative data were collected from primary and secondary sources. The data generated using the questionnaire were organized and coded to investigate the means of solid waste disposal andthe public awareness about the serious challenges of solid waste pollution. The questionnaires were also used to unveil the root causes of the misconception about the deep-rooted culture of open air solid waste burning. The data collected onsite by sorting identification and weighing of the solid waste were used to evaluate solid waste composition/proportion.

\section{Results and Discussion}

\section{Solid waste composition}

The dominant components of solid waste in the town, from repeatedly sampling, were plastics and packaging, leftover foods, old clothes and shoes, pieces of metals and fruits, leaves and vegetables. Plastics and festal; fruits, chat leaves and vegetables; and metals and cans respectively make up $48( \pm 5) \%, 18( \pm 2) \%$ and $11( \pm 3) \%$ of the solid waste pool (Figure 1A). Majority of the solid waste was found to be non-biodegradable $(64 \pm 10 \%)$ whereas about $4 \%$ of the solid wastes are identified as hazardous, which most of them are obsolete electronic devices and household appliances (Figure 1B). Majority of the nonbiodegradables are mainly composed of plastics used for packaging and as containers as the area is the center of border smugglers. About $32 \%$ of the solid wastes are biodegradables, mainly composed of leaves and leftover foods. According to Gardner [4], composting is an ancient practice where more cities in the world now aday are reclaiming the benefits of reusing solid organic waste material. However, in Bule Hora, it is hard see people engaged in such kind of practice.

\section{Solid waste disposal systems}

The most common solid waste disposal mechanisms identified were open field disposal, waste collectors, open air burning in their garden and arbitrary throwing. Of which, open air burning (42\%) followed by surface disposal (36\%), which later will be burnt, were found to be the most common solid waste disposal practices in the town (Figure 2). Only $14 \%$ percent of the respondents collect solid wastes at home and give to waste collectors; whereas about $8 \%$ of the respondents throw solid and liquid waste arbitrary to their surroundings (Figure 2). It is clear to see that about $78 \%$ of the solid waste is managed by burning. Such kind of improper practiceis very common solid waste disposal mechanism in many developing countries around the world [5].

However, open air burning of solid waste has serious human and environmental health consequences. Even those solid wastes seemingly harmless like paper, cardboard, yard waste, and construction debris releases a hazardous mixture of cancer-causing compounds and other toxic substances when open-burned [6]. Pollutants from solid waste burning vary depending on the type of waste materials burned but, typical emissions with high health risk include dioxins, ash, furans, halogenated hydrocarbons, carbon monoxide, lead, barium, chromium, cadmium, arsenic or mercury, acid vapours and carcinogenic tars [6,7]. Because of its hazard, in many nations around the world, particularly in developed world, solid waste open air burning is prohibited except for few non-hazardous wastes below the WHO standards.

In the study area, probably everywhere in developing countries, majority of the respondents say "We've been burning garbage for ages, so what's the big deal now?".

\section{The root causes of solid waste challenge}

Solid waste pollution is the most remarkable type of environmental pollution in the town. About $42 \%$ and $20 \%$ of the respondents believe that lack of awareness and lack of opportunity are respectively are the major causes of environmental pollution (Figure 3). Associated with lack of awareness, many people recklessly pollute their own environment. The respondents also believe an increasing population number and the 


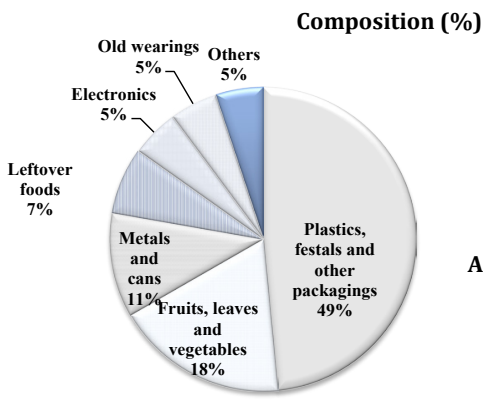

\section{Category of solid waste (\%)}

$\square$ Non-biodegradales $\sqcup$ Biodegradables ⿶ Hazardous wastes

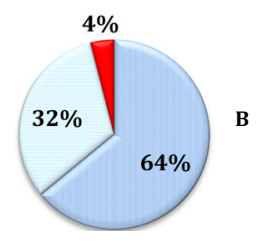

Figure 1: Solid waste composition by weight $(\%)$

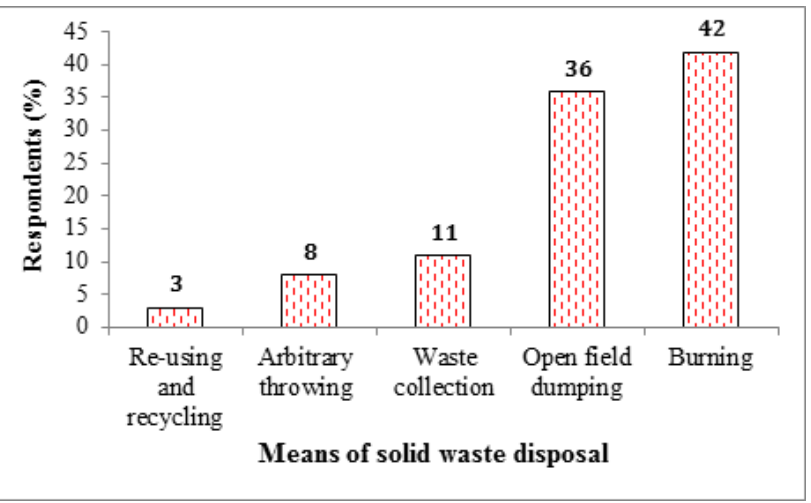

Figure 2: Solid waste disposal systems by percentile.

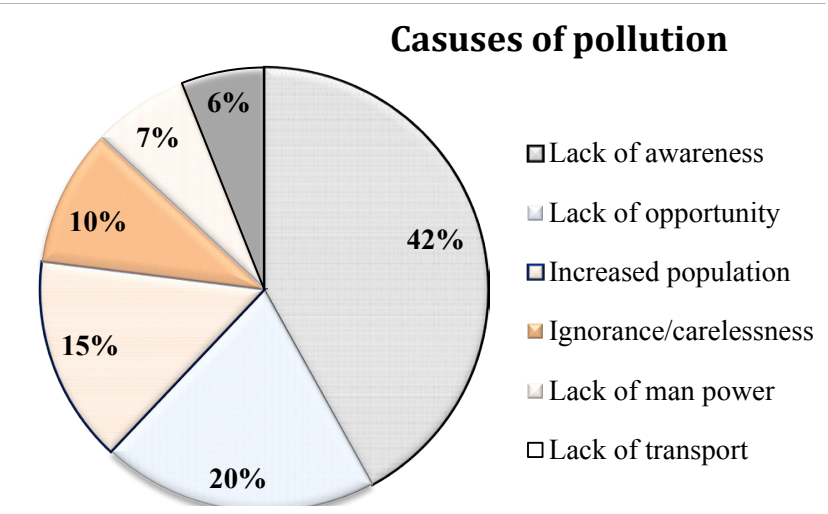

Figure 3: Public responses to the causes of solid waste pollution.

high density considerably contribute to the environmental degradation. However, only few people believe that lack of man power (7\%) and transport $(6 \%)$ could be the reason for the current environmental pollution (Figure 3).

\section{Public awareness to environmental degradation}

Awareness of the community regarding their knowledge about the environment, air pollution, water pollution and soil/land pollution were examined. The response (according to the scales given: scores $>50 \%=$ good; scores $20-50 \%=$ fair and scores $<20 \%=$ No enough knowledge) showed that majority of the respondents have no enough knowledge, particularly majority of the respondents (58\%) lacked the minimum knowledge about air pollution (Figure 4). Respondents have better knowledge about soil/land pollution (32\% good, $45 \%$ fair and $23 \%$ no enough knowledge) which may be due to the fact that soil pollution is most outwardly visible and easily recognizable type of pollution.

The lowest awareness to air pollution may be attributable to the less visibility and many people, particularly illiterate parts of the society, think that everything released to the atmosphere does not have a chance to come back and hence never affect whatever on the ground. In fact this is absolutely wrong understanding which has undisputable impact on the environment. Public awareness and attitudes about waste can affect the whole solid waste management systems [8].

\section{Public concern to current environmental degradation}

The concern (feeling of responsibility) of the people towards the increasing environmental degradation in the town was examined. The two categories of the society (ages above 40 and under 40) showed incredible discrepancies regarding their concern to environmental pollution and its consequences. Respondents under the age of forty generally are concerned about the loss of environmental quality, environmental pollution and its impacts on human health (Figure 5). However, people above the age of forty showed low concern to environmental pollution and its consequences except that $36.5 \%$ are concerned to human health problems. The high feeling of responsibility and concern of the people towards the current environmental degradation under forty years may be due to the fact that this population group has got better formal /informal education. Moreover, they have better exposure to media and communication [9].

\section{Why solid waste burning is more common?}

Solid waste disposal by burning has long tradition in Ethiopia. Although the practice has a sort of decline in the present era, in few cities of the country, collecting solid waste for a long time and burning, predominantly during the month of December, is the most common practice in all towns of the country including the capital city, Addis Ababa. In Bule Hora Town, it is not different. What is special in Bule Hora is that open air burning of all types of solid wastes in every parts of the town is a day to day activity. For the respondents under the age of forty (40\%), people burn everything as a means of disposal system mainly because of the lack of appropriate knowledge about environmental pollution and the bad traditional fixation (30\%) (Figure 6). This may be due to the fact that people have better awareness about environment and better level of education. However, for many people above the age of forty, the main reason for open air burning of wastes, particularly during the month of December is due to the long standing tradition (50\%), but for 35\% of the respondents, in fact the practice has religion attributes and hence, it is a mandatory practice, which in fact has no religion bases their belief (Figure 6).

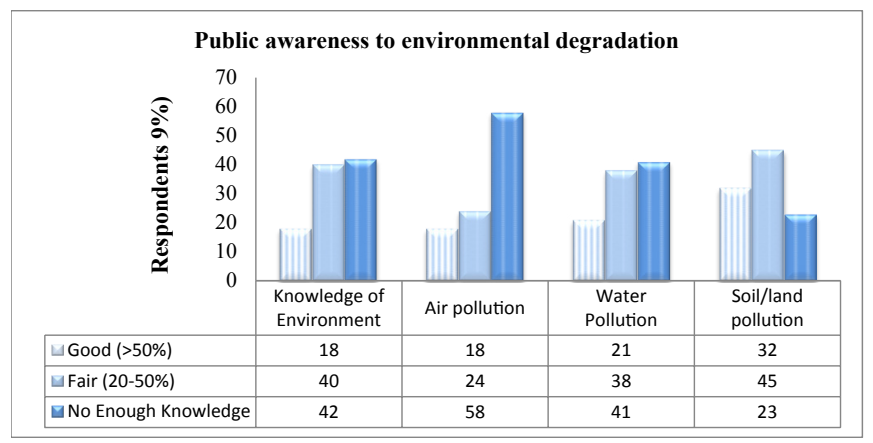

Figure 4: Percentage public awareness to the different types of pollution. 


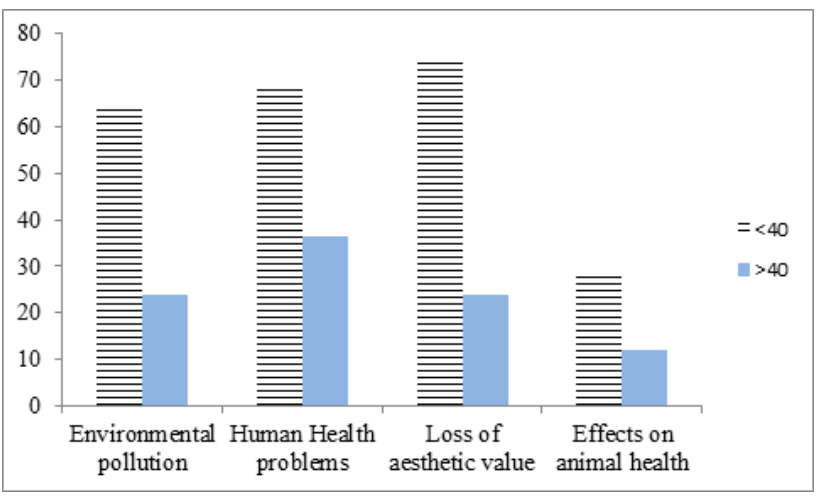

Figure 5: Public concern to the increasing effects of solid waste effect.

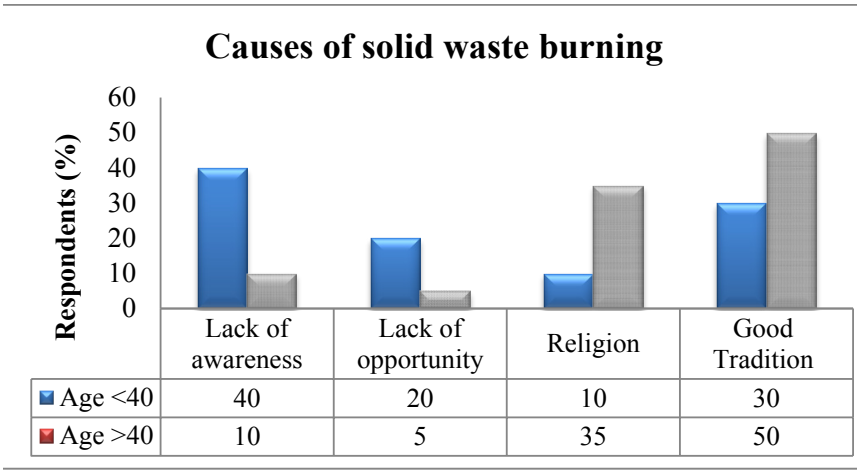

Figure 6: Causes of solid waste burning.

\section{Serious environmental issues in the study area due to open} dumping

Improper solid waste disposal is creating serious negative impacts on environment in Bule Hora Town. The most observable environmental impacts include the following.

- Total loss of aesthetics: It is possible to see solid wastes including papers, chat leaves, packing materials, old wears, leftover foods, festal and other plastic materials scattered everywhere on the surface and partly buried in the dusty soil. This condition makes the environment very repellant and offensive.

- Sewerage system closure: Sewerage systems are blocked by solid wastes and hence, surface run off very common during rainy months and this in turn makes the environment very muddy and appalling.
- Dust and filthy dirt: Strong wind and storm are spreading dust and filth from the open dumps of solid waste to adjacent areas. Flies, Rats and other Vermin: Open dumps everywhere of communal solid waste are providing attractive habitat to flies, rats and other vermin.

- Toxic gases: Toxic gases are continuously exposed to the atmosphere.

- Health and sanitation: Open dumps of solid waste are a serious threat to human health and sanitation

\section{Conclusion}

- Majority of the solid waste scattered everywhere in the town is composed of dangerous materials (non-biodegradables and hazardous materials) that will stay hundreds of years in the environment.

- Public awareness and concern to different aspects of the environmental degradation is very low. However, there is a hope that people under lower age have better awareness and concern.

- Although the solid waste disposal system is inappropriate, majority of the people believe that the solid waste disposal systems are not their major concern, particularly open air burning is the most acceptable.

\section{References}

1. Sakurai S (2000) Municipal Solid Waste Management in Developing Countries - Towards More Efficient International Cooperation. Waste Manag Res 11 142-151.

2. World Bank Group (2018) Ethiopia Urbanization Review: Urban Institutions for a Middle-Income Ethiopia.

3. Cochran G (1977) Sampling Techniques (3rd edn.). Wiley Series, New York USA.

4. Gardner JM (2001) Mud Volcanoes Revealed and Sampled on the Western Moroccan Continental Margin. Geophysical Research Letters 28: 339-342.

5. Ejaz N, Akhtar N, Nisar H, Naeem UA (2010) Environmental Impacts of Improper Solid Waste Management in Developing Countries: A Case Study of Rawalpindi City. WIT Transactions on Ecology and the Environment, WIT Press.

6. Government of Canada (2015) Open Burning of Garbage: Health and Environmental Risks.

7. Wisconsin Department of Natural Resources (2013) Health and Environmental Effects of Open Burning.

8. Zhu B, Pennack JA, McQuilton P, Forero MG, Mizuguchi K, et al. (2008) Drosophila Neurotrophins Reveal a Common Mechanism for Nervous System Formation. PLoS Biol 6: e284.

9. Nigatu R, Rajan DS, Bizunesh BS (2011) Challenges and Opportunities in Municipal Solid Waste Management: The Case of Addis Ababa City, Central Ethiopia. J Hum Ecol 33: 179-190. 